\title{
Burkholderia Pseudomallei Short-Chain Dehydrogenase/ Oxidoreductase: Potential Urine Biomarker Candidate for Acute Melioidosis
}

\author{
Aniza P. O. ${ }^{\text {, }}$, Vanitha M. ${ }^{\text {, }}$, How S. H. ${ }^{\text {, }}$ Mohammed Imad A. M. M. ${ }^{\text {a }}$ \\ ${ }^{a}$ Department of Basic Medical Sciences, Kulliyyah of Medicine, International Islamic University Malaysia Kuantan Campus, \\ ${ }^{b}$ Centre of Toxicology and Health Risk Studies (CORE), Faculty of Health Sciences, National University of Malaysia, Kuala Lumpur \\ 'Department of Internal Medicine, Kulliyyah of Medicine, International Islamic University Malaysia Kuantan Campus
}

\begin{abstract}
Keywords

Burkholderia pseudomallei, biomarker,

melioidosis, urine sample

Corresponding Author

Dr. Aniza bt. P. Oothuman

Department of Basic Medical Sciences,

Kulliyyah of Medicine, International

Islamic University Malaysia Kuantan

Campus, Pahang, Malaysia

Tel No: +6095706400 ext 2012

E-mail: anizapo@iium.edu.my

Received: 28 October 2020; Accepted: 24 May 2021

Doi: https://doi.org/10.31436/imjm.v20i3

INTRODUCTION: In the current climate of urgency in identifying biomarkers for the development of rapid diagnostic kits, the use of urine samples to diagnose acute melioidosis was evaluated, comparing urine samples from Burkholderia pseudomallei culture-positive and culture-negative patients, and comparing pneumonic and septicemic melioidosis. MATERIAL AND METHODS: Eleven urine samples from clinically suspected melioidosis patients from a tertiary referral center, Hospital Tengku Ampuan Afzan, Pahang was used. An in-solution method for the detection of bacterial proteins using liquid chromatography-mass spectrometry quadrupole time-of-flight (LCMS QTOF) was used. RESULTS: Three bacterial proteins were consistently detected among all the culturepositive and PCR-positive cases tested, namely SDR family NAD(P)-dependent oxidoreductase protein $(32 \mathrm{kDa})$, 3-hydroxyacyl-CoA dehydrogenase Burkholderia sp. $(32 \mathrm{kDa})$, and $\mathrm{NAD}(\mathrm{P})$-dependent dehydrogenase (short-subunit alcohol dehydrogenase family) Burkholderia sp. (33kDa). CONCLUSIONS: Short-chain dehydrogenase (SDO) proteins could potentially be a urine biomarker candidate as these have shown to aid in the ability of Burkholderia spp. to invade host cells as this action is important for the initial intracellular survival of the organism.
\end{abstract}

\section{INTRODUCTION}

Melioidosis, an illness caused by the soil saprophyte Gram-negative Burkholderia pseudomallei, is endemic in Southeast Asia, northern Australia and is also commonly found in other tropical and subtropical countries. $^{1}$ The Center for Disease Control and Prevention (CDC) has stated that melioidosis is an emerging infectious disease due to its high infection rate, aerosol infectivity, and intrinsic resistance to a large number of antimicrobial agents. ${ }^{2}$

Melioidosis can occur in any age group; however, in Malaysia, the peak of incidences of cases occur among the age group ranging from 40 to 60 years. ${ }^{3}$ The disease is characterised by acute pneumonia or in some cases more severe systemic infection. ${ }^{1}$ The three modes of transmission of this organism are through contact with contaminated soil or water, inhalation, and less frequently by ingestion. The majority of the cases in endemic areas occur in people with regular contact with contaminated soil or water, via penetrating wounds or pre-existing skin abrasions. ${ }^{4}$ The other common route of entry is the inhalation of contaminated dust or water in muddy and humid conditions during heavy rainfall Heavy monsoon rains cause the bacteria to be concentrated on the surface of the soil, aerosolizing the bacteria, increasing the potential of exposure and transmission. B. pseudomallei bacteria in the infected persons has the ability to remain persistent at a high rate causing relapse incidences despite appropriate antibiotic treatment. ${ }^{4}$ It is also a major concern that to date there is no vaccine available for melioidosis. ${ }^{5}$

A recent study on melioidosis carried out in Kelantan, a northern state in Malaysia between 2001 and 2015 
found that $74.7 \%$ of melioidosis patients had the associated risk factor which is mainly diabetes mellitus, and the mortality rate in the state was $32.9 \%{ }^{6}$ Hence, a high index of suspicion needs to be practiced by physicians and family medicine specialists while diagnosing patients with melioidosis in Pahang (also a state on the East coast of Malaysia) in an attempt to reduce the high rate of mortality among the susceptible diabetic patients. In fact in Pahang, melioidosis has been registered as a notifiable disease. ${ }^{7}$

Diagnosis of melioidosis can be difficult and timeconsuming, as the bacterium may not be readily isolated from clinical specimens from patients suspected of melioidosis. Moreover, laboratory bacterial culture methods can only detect a positive culture for $B$. pseudomallei after a minimum of 3 to 4 days after infection, and it is possible that the laboratory personnel may misidentify B. pseudomallei. ${ }^{8}$ The more rapid polymerase chain reaction (PCR) assays for direct detection of B. pseudomallei from blood and sputum samples are also often associated with suboptimal sensitivities and specificities ${ }^{8}$ and may not be available in the district hospitals in Malaysia.

In general, urine is not the most appropriate fluid sample from patients suspected of melioidosis to be used for diagnosis purposes, unless there is urinary tract involvement. However, B. pseudomallei proteins were present in the urine samples of several of the melioidosis patients from Hospital Tengku Ampuan Afzan (HTAA). Thus, it is hypothesised here that even in the absence of the bacteria in the urine (or presence of localised infection), there are potentially novel proteins that are specifically produced by B. psendomallei that may be detected from urine samples. It is important to search for these potential biomarkers in order to prepare a diagnostic kit for diagnosing melioidosis.

Thus, this study aimed to attempt to detect the $B$. pseudomallei proteins present in the urine samples obtained from patients suffering from acute pulmonary and septicaemic melioidosis. This was done by gel-free in-solution methods using liquid chromatography-mass spectrometry quadrupole time-of-flight (LCMS-QTOF) analysis. By using a simple, detergent-free, acetonebased protein extraction and purification method, after desalting and tryptic digestion, urine proteome was extracted from acute melioidosis cases, comparing those from B. pseudomallei culture-positive and culturenegative patients.

\section{METHODOLOGY}

\section{Ethics declaration}

This study was undertaken with ethical approval from the Ministry of Health Malaysia's Medical Research and Ethics Committee (MREC), the National Medical Research Register (NMRR) ID: NMRR-16-2699-33554. Informed written consent was obtained from all patients.

\section{Sample collection}

A total of 11 urine samples, i.e. 8 culture-positive cases (MEL-1 to MEL-8) and 3 culture-negative cases (NM-1 to NM-3) were collected from acute melioidosis patients diagnosed clinically by physicians upon admission in HTAA, Pahang. Although the sample collection period was 18 months, we had unexpected difficulties getting more positive cases due to various reasons (patients refusing consent, patient mortality before diagnosis, transfer to private healthcare facilities, treated at district hospitals).

Patients were recruited based on the presence of symptoms of pneumonia (cough, breathlessness, pleuritic chest pain in the preceding four weeks) or septicaemia (two or more of body temperature below $36{ }^{\circ} \mathrm{C} /$ above $38^{\circ} \mathrm{C}$; heart rate $>90 \mathrm{bpm}$; respiratory rate $>20$ / minute), along with evidence of alveolar infiltrate on chest radiograph within 48 hours of admission. Any related co-morbidities like diabetes, hypertension, kidney disease, and immunosuppression were also recorded (Table 1). After recruitment of subjects the midstream urine samples of patients were collected in a sterile urine collection container and kept at $4-8^{\circ} \mathrm{C}$. These urine samples were centrifuged at $2500 \mathrm{rpm}$ (Beckman Coulter Allegra X-12R, USA) and the resultant pellet was discarded and the supernatant was stored at $-80{ }^{\circ} \mathrm{C}$ until commencing proteomic sample preparation. 


\section{B.pseudomallei PCR detection}

Positive and negative cases of melioidosis were identified using bacterial cultures and PCR. The Mediven GenoAmp ${ }^{\circledR}$ Real-Time PCR Tropical Fever Kit (Mediven, Malaysia) according to the manufacturer's protocol with the Taqman hydrolysis probe-based platform was used, and the primer was used for B. psendomallei type III secretion system gene cluster (GenBank accession number AF074878) of B. psendomallei. Culture for B. psendomallei was done using Francis media ${ }^{8}$ by the Pathology Department of HTAA.

\section{Liquid chromatography-mass quadrupole time-of-flight analysis}

spectrometry

A modified method by Kim et al. (2006) ${ }^{9}$ was used with a preparation in the absence of denaturants since LCMS -QTOF set-ups do not allow for the presence of detergents. The protein content (as in Table 2) in each of the centrifuged urine samples was measured using a micro-volume spectrophotometer (SpectraMax ${ }^{\circledR}$ QuickDrop ${ }^{\mathrm{TM}}$, USA). The amount of urine sample used differed according to each sample concentration (calculated individually) to have a final concentration of $5 \mathrm{mg} / \mathrm{ml}$. Then the protein clean-up process was done using the BioRad ReadyPrep ${ }^{\circledR}$ 2-D Clean-up Kit (BioRad, USA), which uses acetone and trichloroacetic acid (TCA), based precipitation agents. Protein denaturation was performed using iodoacetamide (IAA) and dithiothreitol (DTT).

Buffers used were prepared using $6 \mathrm{M}$ urea in $50 \mathrm{mM}$ Tris-HCl (pH8.0). MS grade trypsin was used for protein digestion and Millipore ZipTips ${ }^{\circledR}$ (Merck, USA) was used for desalting of the digested peptides. Elution buffer used was $60 \%$ acetonitrile/ $0.1 \%$ formic acid. The samples were then run in the Agilent 1200 HPLC-Chip/MS Interface (Agilent, USA), coupled with Agilent 6550 iFunnel Q-TOF LC/MS (Agilent, USA). The LC column used was the Agilent large capacity chip, 300 Ampere, C18, 160nL enrichment column, $75 \mathrm{um} \times 150 \mathrm{~mm}$ analytical column, with a flow rate of $4 \mu \mathrm{L} / \mathrm{min}$ from Agilent 1200 Series Capillary Pump, and $0.5 \mu \mathrm{L} / \mathrm{min}$ from Agilent 1200 Series Nano
Pump. Settings on the gradient and time were adapted from Gautam et al ${ }^{10}$ and Juvarajah et al. ${ }^{11}$

For MALDI TOF analysis, the sample protein preparation method was used as LCMS. MS analysis was carried out on a 5800 Plus MALDI TOF/TOF analyzer (Sciex, Framingham USA) equipped with TOF -TOF ion optics and OptiBeam ${ }^{\mathrm{TM}}$ on-axis laser irradiation with $1000 \mathrm{~Hz}$ repetition rate. The system was calibrated immediately before analysis with a mixture of calibrant of mass standard kit purchased from Sciex, Framingham, USA (Product No 4333604). MS spectra were acquired in the positive reflector mode by summarising 1000 single spectra $(8 \times 125)$ in the mass range from 700 to $4000 \mathrm{Da}$. MS/MS spectra were acquired in the positive MS/MS reflector mode by summarising a maximum of 2500 single spectra $(10 \times$ $250)$ with precursor ion selection of 20 strongest peaks. For the tandem MS experiments, the acceleration voltage applied was $1 \mathrm{kV}$ and the air was used as the collision gas.

\section{Protein detection and statistical data analysis}

Data from the LCMS QTOF MS was processed with PEAKS STUDIO X SPIDER database software, searching in human and B. pseudomallei database. Precursor charge state set at 2,3>3, missed cleavages 2 , precursor mass error ppm 25, peptide mass error tolerance (Da) at 0.1. False discovery rate (FDR) was set at 0.1 , while average local confidence (ALC) scores of peptide sequence matches (PSM) were set at $\geq 50 \%$. The database type was Swissprot and TrEMBL, fixed modification; in solution; carbamidomethylation.

For MALDI TOF MS/MS, the spectra were processed

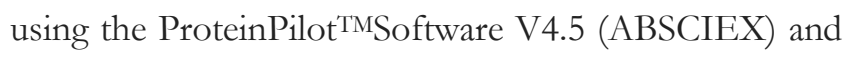
subsequently executed to database searching using Mascot 2.2 program (Matrix Science). The probability MOWSE (Molecular Weight Search) histograms were generated for each sample with the generation of a score of statistical significance.

\section{RESULTS}

In this study, 8 culture-positive samples were obtained and 3 culture-negative cases were included for 
comparison. All clinically suspected melioidosis cases recruited from HTAA were treated with the broadspectrum antibiotic ceftazidime, even though samples were finally both culture and PCR negative for $B$. pseudomallei. Table 1 shows the demographics of the 11 patients recruited, and their median age in total was 53.7 years. Seven out of the eight culture-positive patients were males. Six out of eight $(75 \%)$ culture-positive patients were diabetic, and the three culture-negative samples (patients) included were all diabetics (agematched using the range of age). Half of the culturepositive patients presented with septicaemia, and 75\% of culture-positive had underlying kidney disease prior to admission. that seen in those with diabetic nephropathy, acute kidney injury, and systemic inflammation. 13

Among the culture-positive cases, five out of eight samples (Table 3), showed the same PSMs from the $B$. pseudomallei database on PEAKSX Studio (SPIDER database), meanwhile, one sample (MEL-2) had no PSMs for B. psendomallei, and additionally, one sample MEL-7, had a different database hit from the others. Two uncharacterised proteins were detected, and in the meantime, other protein database matches were for non -ribosomal peptide synthetase and ABC-transporter substrate-binding protein.

Table 1: Clinical parameters of melioidosis cases recruited in this study

\begin{tabular}{|c|c|c|c|c|c|}
\hline & & \multicolumn{2}{|c|}{ Melioidosis Culture } & \multicolumn{2}{|l|}{ PCR } \\
\hline & & POS & NEG & POS & NEG \\
\hline Subjects & & 8 & 3 & 6 & 5 \\
\hline \multirow[t]{2}{*}{ Gender } & Male & 7 & 2 & 5 & 4 \\
\hline & Female & 1 & 1 & 1 & 1 \\
\hline Age in years: mean (median) & & $51(49)$ & $61(65)$ & $51(47)$ & $56(55)$ \\
\hline \multirow[t]{2}{*}{ Diabetes mellitus } & Yes & 6 & 1 & 4 & 5 \\
\hline & No & 2 & 2 & 2 & 0 \\
\hline Days of fever: mean (median) & & $8.7(7)$ & $7.0(6)$ & $9.2(5)$ & $7.5(7)$ \\
\hline \multirow[t]{2}{*}{ Kidney disease } & Yes & 4 & 2 & 3 & 3 \\
\hline & No & 4 & 1 & 3 & 2 \\
\hline \multirow[t]{2}{*}{ Diagnosis } & Septicaemia & 4 & 2 & 2 & 3 \\
\hline & Pneumonia & 4 & 1 & 4 & 2 \\
\hline
\end{tabular}

Among the diabetic patients, seven out of eight had high protein concentrations (above $20 \mathrm{mg} / \mathrm{dL}$ ) in their urine and five out of six patients recruited with known kidney disease had high protein concentrations ( $22.73-$ $41.67 \mathrm{mg} / \mathrm{ml}$ ) in the urine also (Table 2); however, the only one patient who was diagnosed with septicaemic melioidosis had high urine protein concentrations (29.97 $\mathrm{mg} / \mathrm{ml}$ ) and was also having secondary infection with Burkholderia cepacia. Two patients were culture positive for B. pseudomallei, but were negative in PCR analysis for B. psendomallei. This is a known problem in the current diagnostics scenario, as the bacterium has been known to 'evade' detection by the PCR method, but still be detectable by the culture method. ${ }^{12}$

Many peptide spectrum matches (PSM) were detected in each sample, as seen in Supplementary Figure 1. The urine proteome of acute melioidosis cases was a mix of
Among the samples which were culture-negative (and PCR negative) for B. pseudomallei, the proteins detected were different among the three samples, as shown in Table 4. Unlike the almost uniform detection of similar proteins in the culture-positive cases, these database hits seem one-off in the case of Burkholderia protein detection. Proteins detected via MALDI TOF MS/MS for all the samples are listed in Supplementary Table 2.

\section{$\underline{\text { MALDI TOF MS/MS results }}$}

Numerous Swissprot database hits were obtained (Supplementary Table 2) for B. pseudomallei specific proteins using MALDI TOF MS/MS. However, no statistically significant scores were obtained for the proteins. The range of molecular weights is between $4 \mathrm{kDa}$ and $156 \mathrm{kDa}$, a range quite large. Uncharacterised proteins of B. pseudomallei were detected with convincing 
Table 2: The clinical data among recruited patients, and the concentration of urine calculated using a nano-spectrophotometer. (Note: According to medlineplus.gov, a random normal urine sample may contain $0-20 \mathrm{mg} / \mathrm{dL}$ of protein content); (*) denotes the above-normal amount of protein concentration in urine; $(N G=$ no growth; $P O S=$ positive; $N E G=$ negative).

\begin{tabular}{ccccccccc}
\hline Sample & Age & $\begin{array}{c}\text { Diabetes } \\
\text { Mellitus }\end{array}$ & $\begin{array}{c}\text { Kidney } \\
\text { disease }\end{array}$ & Diagnosis & $\begin{array}{c}\text { Melioidosis } \\
\text { Culture }\end{array}$ & $\begin{array}{c}\text { Melioidosis } \\
\text { PCR }\end{array}$ & $\begin{array}{l}\text { Other culture } \\
\text { results }\end{array}$ & $\begin{array}{l}\text { Protein } \\
\text { concentration } \\
\text { in urine (mg/ } \\
\text { dl) }\end{array}$ \\
\hline MEL 1 & 42 & $\sqrt{(m)}$ & & & & & & $26.53^{*}$ \\
MEL 2 & 65 & $\sqrt{ }$ & $\sqrt{ }$ & Septicemia & POS & POS & NG & 18.12 \\
MEL 3 & 46 & $\sqrt{ }$ & - & Septicemia & POS & POS & NG & $21.33^{*}$ \\
MEL 4 & 47 & - & - & Pneumonia & POS & POS & NG & 20.51 \\
MEL 5 & 44 & $\sqrt{ }$ & - & Pneumonia & POS & POS & NG & $21.52^{*}$ \\
MEL 6 & 50 & $\sqrt{ }$ & $\sqrt{ }$ & Pneumonia & POS & NEG & NG & $22.73^{*}$ \\
MEL 7 & 59 & - & $\sqrt{ }$ & Septicemia & POS & NEG & NG & $34.08^{*}$ \\
MEL 8 & 54 & $\sqrt{ }$ & $\sqrt{ }$ & Septicemia & POS & POS & NG & $25.84^{*}$ \\
NM 1 & 65 & $\sqrt{ }$ & - & Septicemia & NEG & NEG & Pus B.cepacia & $29.97^{*}$ \\
NM 2 & 58 & $\sqrt{ }$ & $\sqrt{ }$ & Pneumonia & NEG & NEG & NG & $41.67^{*}$ \\
NM 3 & 51 & $\sqrt{ }$ & $\sqrt{ }$ & Septicemia & NEG & NEG & Acinetobacter & $33.39^{*}$ \\
\hline
\end{tabular}

peaks but scores did not reach levels of Among culture-positive cases (Figure 1), five out of statistical significance. A notable result eight cases had peptide spectrum matches for A3N889|A3N889_BURP6 (5170Da) the notation for Burkholderia SDR family NAD(P)-dependent Uncharacterised protein OS B. pseudomallei (strain 668) oxidoreductase, compared to the one case among the obtained a score of 44 (score required for statistical culture-negative cases. Similarly, all the same, five significance is 66). Another result with a score of 41 is specimens showed PSMs for 3-hydroxyacyl-CoA Uncharacterised protein OS B. pseudomallei (strain 1710b) dehydrogenase Burkholderia sp, and NAD(P)-dependent $(130 \mathrm{kDa})$.

Table 3: Summary list of the proteins detected using LCMS-QTOF and their molecular mass. (culture-positive cases: MEL-1 to MEL-8).

\begin{tabular}{|c|c|c|c|c|c|c|c|c|c|c|}
\hline Accession & $\begin{array}{l}\text { Avg. Mass } \\
\text { (Dalton) }\end{array}$ & $\begin{array}{l}\text { Description (ID from } \\
\text { SPIDER DB PeaksStudio) }\end{array}$ & $\begin{array}{l}\text { ME } \\
\text { L-1 }\end{array}$ & $\begin{array}{l}\mathrm{ME} \\
\mathrm{L}-2\end{array}$ & $\begin{array}{l}\text { ME } \\
\text { L-3 }\end{array}$ & $\begin{array}{l}\mathrm{ME} \\
\mathrm{L}-4\end{array}$ & $\begin{array}{l}\text { ME } \\
\text { L-5 }\end{array}$ & $\begin{array}{l}\text { ME } \\
\text { L-6 }\end{array}$ & $\begin{array}{l}\text { ME } \\
\text { L-7 }\end{array}$ & $\begin{array}{l}\mathrm{ME} \\
\mathrm{L}-8\end{array}$ \\
\hline $\begin{array}{l}\operatorname{tr} \mid \text { A0A3N8GRM6 } \mid \text { A0 } \\
\text { A3N8GRM6_9BURK }\end{array}$ & 32324 & $\begin{array}{l}\text { SDR family NAD }(\mathrm{P}) \text { - } \\
\text { dependent oxidoreductase } \\
\text { Burkholderia sp. }\end{array}$ & $\sqrt{ }$ & & $\sqrt{ }$ & $\sqrt{ }$ & $\sqrt{ }$ & & & $\sqrt{ }$ \\
\hline $\begin{array}{l}\operatorname{tr}|\mathrm{A} 0 \mathrm{~A} 1 \mathrm{~V} 2 \mathrm{XNF} 4| \mathrm{A} 0 \mathrm{~A} \\
\text { 1V2XNF4_9BURK }\end{array}$ & 32097 & $\begin{array}{l}\text { 3-hydroxyacyl-CoA } \\
\text { dehydrogenase Burkholderia } \\
\text { sp. }\end{array}$ & $\sqrt{ }$ & & $\sqrt{ }$ & $\sqrt{ }$ & $\sqrt{ }$ & & & $\sqrt{ }$ \\
\hline $\begin{array}{l}\operatorname{tr} \mid \text { A0A364GXA5 } \mid \text { A0A } \\
\text { 364GXA5_9BURK }\end{array}$ & 33274 & $\begin{array}{l}\text { NAD }(\mathrm{P}) \text {-dependent } \\
\text { dehydrogenase (Short- } \\
\text { subunit alcohol } \\
\text { dehydrogenase family) } \\
\text { Burkholderia sp. }\end{array}$ & $\sqrt{ }$ & & $\sqrt{ }$ & $\sqrt{ }$ & $\sqrt{ }$ & & & $\sqrt{ }$ \\
\hline $\begin{array}{l}\operatorname{tr} \mid \text { A0A095FA46|A0A0 } \\
\text { 95FA46_BURCE }\end{array}$ & 32309 & $\begin{array}{l}\text { Short-chain dehydrogenase } \\
\text { family protein } \\
\text { OS=Burkholderia sp. }\end{array}$ & & & & $\sqrt{ }$ & $\sqrt{ }$ & & & $\sqrt{ }$ \\
\hline $\begin{array}{l}\operatorname{tr} \mid \text { G8MPG0|G8MPG0 } \\
\text { _9BURK }\end{array}$ & 16807 & $\begin{array}{l}\text { Uncharacterised protein } \\
\text { OS=Burkholderia sp. }\end{array}$ & & & & $\sqrt{ }$ & & & & \\
\hline $\begin{array}{l}\operatorname{tr} \mid \text { A0A228GDW4 |A0 } \\
\text { A228GDW4_9BURK }\end{array}$ & 481211 & $\begin{array}{l}\text { Non-ribosomal peptide } \\
\text { synthetase OS=Burkholderia } \\
\text { sp. }\end{array}$ & & & & & $\sqrt{ }$ & & & \\
\hline $\begin{array}{l}\operatorname{tr}|\mathrm{A} 0 \mathrm{~A} 063 \mathrm{BE} 92| \mathrm{A} 0 \mathrm{~A} 0 \\
\text { 63BE92_9BURK }\end{array}$ & 33331 & $\begin{array}{l}\text { ABC transporter substrate- } \\
\text { binding protein } \\
\text { OS=Burkholderia sp. }\end{array}$ & & & & & & & $\sqrt{ }$ & \\
\hline $\begin{array}{l}\operatorname{tr} \mid \text { A0A2S9NG99|A0A } \\
\text { 2S9NG99_9BURK }\end{array}$ & 63134 & $\begin{array}{l}\text { Uncharacterised protein } \\
\text { OS=Burkholderia sp }\end{array}$ & & & & & & & & $\sqrt{ }$ \\
\hline
\end{tabular}


Table 4: Burkholderia sp. database matches for samples from culture-negative patients for Bukholderia pseudomallei using PEAKS Studio X SPIDER database

\begin{tabular}{|c|c|c|c|c|c|}
\hline Accession & $\begin{array}{l}\text { Avg. Mass } \\
\text { (Dalton) }\end{array}$ & $\begin{array}{l}\text { Description (ID from SPIDER DB } \\
\text { PeaksStudio) }\end{array}$ & NM-1 & $\begin{array}{l}\text { NM } \\
-2\end{array}$ & $\overline{\mathrm{NM}}-3$ \\
\hline $\begin{array}{l}\text { tr|A0A3N8GRM6|A0A3N8GRM6_ } \\
\text { 9BURK }\end{array}$ & 32324 & $\begin{array}{l}\text { SDR family NAD }(\mathrm{P}) \text {-dependent oxidoreduc- } \\
\text { tase Burkholderia sp. }\end{array}$ & & & $\sqrt{ }$ \\
\hline $\begin{array}{l}\operatorname{tr} \mid \text { A0A1V2XNF4|A0A1V2XNF4_9 } \\
\text { BURK }\end{array}$ & 32097 & $\begin{array}{l}\text { 3-hydroxyacyl-CoA dehydrogenase } \\
\text { Burkholderia sp. }\end{array}$ & & & $\sqrt{ }$ \\
\hline $\begin{array}{l}\text { tr|A0A364GXA5|A0A364GXA5_9B } \\
\text { URK }\end{array}$ & 33274 & $\begin{array}{l}\text { NAD }(\mathrm{P}) \text {-dependent dehydrogenase (Short- } \\
\text { subunit alcohol dehydrogenase family) } \\
\text { Burkholderia sp. }\end{array}$ & & & $\sqrt{ }$ \\
\hline $\begin{array}{l}\text { tr|A0A095FA46|A0A095FA46_BUR } \\
\text { CE }\end{array}$ & 32309 & $\begin{array}{l}\text { Short-chain dehydrogenase family protein } \\
\text { OS=Burkholderia sp. }\end{array}$ & & & \\
\hline $\begin{array}{l}\operatorname{tr}|\mathrm{A} 0 \mathrm{~A} 0 \mathrm{~B} 6 \mathrm{~S} 2 \mathrm{~S} 5| \mathrm{A} 0 \mathrm{~A} 0 \mathrm{~B} 6 \mathrm{~S} 2 \mathrm{~S} 5 \text { _9BU } \\
\mathrm{RK}\end{array}$ & 45868 & $\begin{array}{l}\text { Putative biotin carboxylase } \\
\text { OS=Burkholderia sp. }\end{array}$ & $\sqrt{ }$ & & \\
\hline tr|E1TJ96|E1TJ96_BURSG & 74095 & $\begin{array}{l}\text { Fanconi-associated nuclease } \\
\text { OS=Burkholderia sp. }\end{array}$ & $\sqrt{ }$ & & \\
\hline $\begin{array}{l}\operatorname{tr} \mid \text { A0A3N8QQF5|A0A3N8QQF5_9 } \\
\text { BURK }\end{array}$ & 28779 & $\begin{array}{l}\text { TIR domain-containing protein } \\
\text { OS=Burkholderia sp. }\end{array}$ & & $\sqrt{ }$ & \\
\hline $\begin{array}{l}\operatorname{tr} \mid \text { A0A1R3VY63|A0A1R3VY63_9B } \\
\text { URK }\end{array}$ & 26495 & $\begin{array}{l}\text { Outer membrane transport energization } \\
\text { protein ExbB (TC 2.C.1.1.1) } \\
\text { OS=Burkholderia sp. }\end{array}$ & & $\sqrt{ }$ & \\
\hline $\begin{array}{l}\operatorname{tr} \mid \text { A0A1R3WEK1|A0A1R3WEK1_9 } \\
\text { BURK }\end{array}$ & 26496 & $\begin{array}{l}\text { Outer membrane transport energization } \\
\text { protein ExbB OS=Burkholderia sp. }\end{array}$ & & $\sqrt{ }$ & \\
\hline tr|B1YQQ9|B1YQQ9_BURA4 & 53995 & $\begin{array}{l}\text { Putative transcriptional regulator } \\
\text { OS=Burkholderia sp. }\end{array}$ & & $\sqrt{ }$ & \\
\hline $\begin{array}{l}\operatorname{tr} \mid \text { A0A125SES8|A0A125SES8_9BU } \\
\text { RK }\end{array}$ & 30898 & $\begin{array}{l}\text { Dihydropteroate synthase OS=Burkholderia } \\
\text { sp. }\end{array}$ & & & $\sqrt{ }$ \\
\hline
\end{tabular}

dehydrogenase Burkholderia sp. All the other PSMs detected were one-off in single samples. There does not appear to be any correlation with the presence of comorbidities such as diabetes mellitus, hypertension, or others in the detection of the three proteins in the samples. There is no correlation with high urine concentration amounts either (as shown in Table 2) with the detection of the proteins.

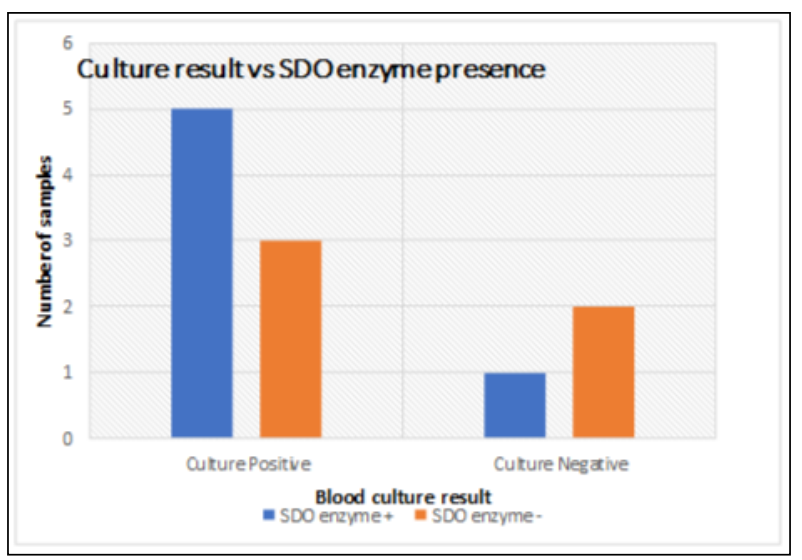

Figure 1: Recruited cases grouped by culture result (tested for Burkholderia pseudomallei using Francis media), with the presence of short-chain dehydrogenase/oxidoreductase (SDO) enzyme.

\section{DISCUSSION AND CONCLUSION}

The urgency for developing a more effective method of diagnosing patients with acute melioidosis is ultimately to catch the more fulminating melioidosis cases that progress very quickly to mortality. Ideally, if a case of melioidosis can be recognised quickly at the level of primary care or district hospitals, many of the serious complications of acute melioidosis may be prevented. Although conventional culture methods are cheaper and less labour-intensive, unfortunately, the time needed is 5-7 days. The search for and identifying biomarkers could present an alternate ideal method for faster diagnosis. Urine is one of the most accessible biomaterials for biomarkers studies and the specimen is less complex to analyse than blood. ${ }^{13}$

The urine culture-positive cases in this study had PSMs for the following 3 Burkholderia proteins, namely SDR family NAD(P)-dependent oxidoreductase, 3hydroxyacyl-CoA dehydrogenase Burkholderia sp, and NAD(P)-dependent dehydrogenase Burkholderia sp. 


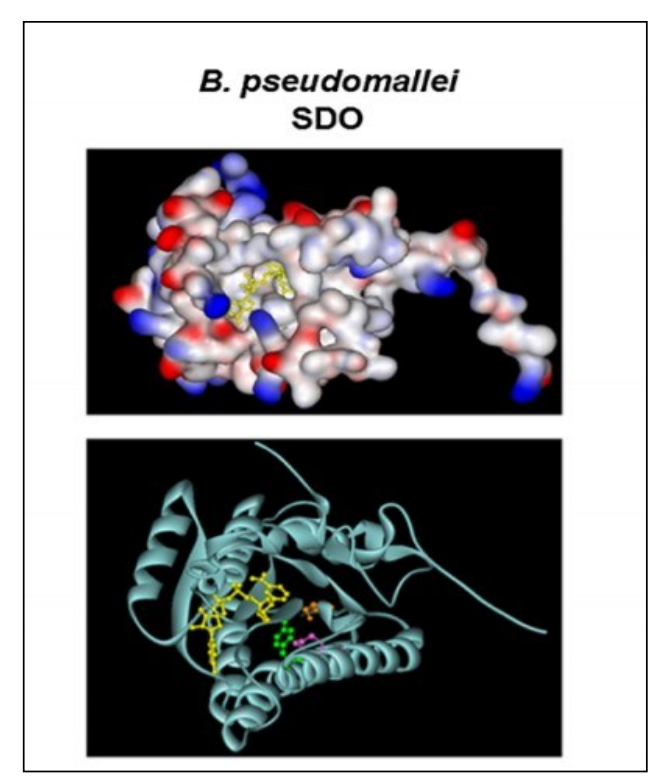

Figure 3: Structural model of B. psendomallei short-chain dehydrogenase/ oxidoreductase (SDO) (Image from Pumirat et al (2014) ${ }^{12}$.

The short-chain dehydrogenase/oxidoreductase (SDO) (Figure 3) is an enzyme in the short-chain dehydrogenases/ reductases /oxidoreductase family that catalyses the bacterial chemical reactions below. ${ }^{17}$

D-glucose $+\mathrm{NAD}+=\mathrm{D}$ - glucono-1,5-lactone $+\mathrm{NADH}+\mathrm{H}+$

The structural model of B. pesudomallei SDO indicates a catalytic triad and cofactor binding domain. There is specificity to beta-D-glucose and is capable of using either $\mathrm{NAD}^{+}$or $\mathrm{NADP}^{+}$as a cofactor, as similarly described in another study with B. megaterium. ${ }^{14}$

Chamchoy et al (2020) studied sequence analysis of SDO protein superfamily of B. pseudomallei and found that overexpression of BPSS2242 (a putative SDR), significantly increased survival rates of E. coli and $B$. pseudomallei K96243.15

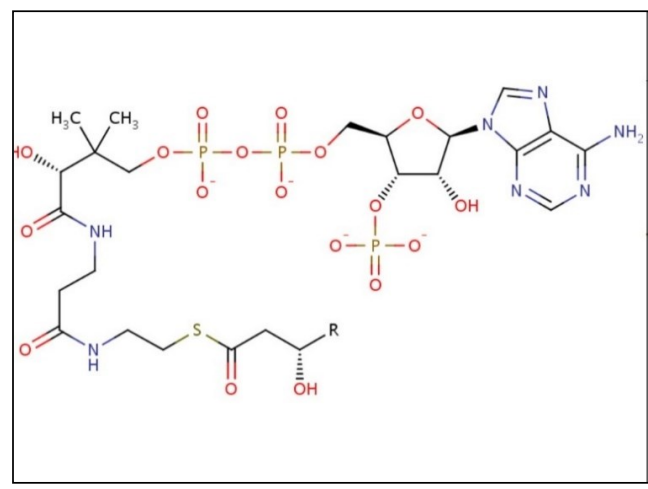

Figure 4: The chemical structure of the protein 3 hydroxyacyl-CoA dehydrogenase (Image from https://www.uniprot.org/uniprot/O02691)
The 3-hydroxyacyl-CoA dehydrogenase (32 kDa protein) enzyme (Figure 4) is involved in the pathway of fatty acid beta-oxidation, which is part of lipid metabolism. Bacterial fatty acid synthesis is essential for many pathogens and they are different from their mammalian counterpart.

NAD(P)-dependent dehydrogenase (short-subunit alcohol dehydrogenase family) is the third Burkbolderia sp. protein constantly detected in five out of eight samples. These three proteins were found among the urine samples from both pneumonic and septicaemic patients. It was only found in the urine of one of the melioidosis culture-negative (and PCR negative) samples. We predict that these could be a potential candidate for biomarkers in diagnosing acute melioidosis.

Pumirat et al. (2014), in their research using microarray analysis, demonstrated up-regulation of SDO, and that B. psendomallei lacking SDO had reduced abilities to invade and establish initial intracellular survival. ${ }^{16}$ This indicates that this $32 \mathrm{kDa}$ enzyme is associated with the pathogenesis of B. pseudomallei, demonstrating that microbial SDOs may provide important information in developing a new strategy for the treatment of melioidosis. ${ }^{16}$ The expression of SDO in B. pseudomallei is increased under salt stress, which is believed to be part of the process for the survival of the organism in the soil environment. However, the direct impact of salt and osmotic stress on B. pseudomallei and its pathogenicity in immunosuppressed patients is still unknown. Sodium levels could be high in sepsis and inflammation, which could be the reason this enzyme has been detected. ${ }^{16}$ However, quantification of this protein to comment on its up-regulation was not done in this study.

In addition, Smith et al. (1996) in their findings suggested that there was a relationship between high salt concentration and susceptibility to bacterial infection, as observed in patients with cystic fibrosis (CF). ${ }^{17}$ Opportunistic lung infections in CF patients have been linked with a variety of pathogens, including B. pseudomallei and other Burkholderia sp. Pumirat et al. (2014) put forward the proposal that SDO is an adaptive determinant of the virulence of B. pseudomallei, 
up-regulated under salt stress and that it plays a significant role in interactions with host cells. ${ }^{5}$

The 3-hydroxyacyl-CoA dehydrogenase is an enzyme involved in the type II fatty acid synthesis (FASII) process, which is used by bacteria to generate fatty acids components of phospholipids. It is possible that in heightened activity during an active infection, it is up -regulated in the host bloodstream. Additionally, acylCoAs are used to support phospholipid synthesis. The FASII genes in Gram-negative bacteria help in assembling the lipid A core structure of outer membrane lipopolysaccharides. ${ }^{15}$

Bacterial fatty acid synthesis inhibitors are singletargeting agents, unlike the traditional monotherapeutic, broad-spectrum antibiotics which are multi -targeting. This single targeting nature makes fastdeveloping, target-based resistance a necessary consideration for antibiotic development or adjuvant therapies. ${ }^{15}$ B. pseudomallei may not be exhibiting resistance tendencies presently, but it is probably just a matter of time before it occurs. Specific targeting of pathogens together with advanced diagnostic methods either by detection of bacterial genes or their byproducts in a more rapid manner could be a promising future in diagnosing melioidosis.

NAD(P)-dependent dehydrogenase (short-subunit alcohol dehydrogenase family) is part of an abundant group of enzymes that catalyse the conversion between alcoholic compounds and their corresponding aldehydes or ketones, a process which is essential for many living organisms. ${ }^{14}$

It is increasingly apparent that many of the bacteria in the Burkholderia family share very similar proteins ${ }^{18}$, and it is quite difficult to find proteins that are almost unique to one species, as multiple hits on uniprot.org pointed to this protein but of multiple different species of Burkholderia.

It is possible that the larger and more abundant urinary proteins such as albumin and uromodulin may have masked the signals of the lower abundant proteins. Using molecular weight cut-off (MWCO) filters may increase the pick-up of low molecular weight signals.
Young et al (2014), in their study (using 2D electrophoresis, HPLC, and MS) compared active tuberculosis (TB), latent TB, and normal patient groups, and they found 10 proteins unique to the active TB group, six unique to the latent group and three to the non-TB group. The proteins found were involved in defense, immune and cellular responses, among others. ${ }^{19}$

In conclusion, based on the analyses in this study, it is proposed that the following three proteins: SDR family NAD(P)-dependent oxidoreductase, 3-hydroxyacyl-CoA dehydrogenase Burkholderia sp, and NAD(P)dependent dehydrogenase Burkholderia sp. may be collectively used to diagnose acute melioidosis cases using urine samples of patients in the lateral flow immunoassay or ELISA. However, this proposal needs confirmation supported by further studies with larger sample size.

\section{ACKNOWLEDGEMENT}

A special thanks to Dr. Roesnita, a microbiologist from HTAA Kuantan, Pahang for providing culture results of patients.

\section{AUTHORS' CONTRIBUTIONS}

Overall coordination: APO, VM, HSH, IMD. Performed experiments: APO. Analysed the data: APO. Contributed reagents/ materials/ analysis tools: VM. Drafted the paper: APO, VM. Final manuscript: APO, VM, HSH, IMD. All authors read and approved the final manuscript.

\section{REFERENCES}

1. Wiersinga WJ, Virk HS, Torres AG, Currie BJ, Shoron J, Dance DAB, et al. HHS Public Access. 2019;

2. Cheng AC, Currie BJ, Dance DAB, Funnell SGP, Limmathurotsakul D, Simpson AJH, et al. Clinical definitions of melioidosis. Am J Trop Med Hyg. 2013;88(3):411-3.

3. Nathan S, Id SC, Kingsley PV, Id AM, Podin Y, Ooi M, et al. Melioidosis in Malaysia: Incidence, Clinical Challenges, and Advances in Understanding Pathogenesis. 2018; 
4. Cheng A, Currie B. Melioidosis: epidemiology, pathophysiology, and management. Clin

Microbiol Rev [Internet]. 2005;18(2):383-416.

Available from: http://cmr.asm.org/ content/18/2/383.short

5. Choh LC, Ong GH, Vellasamy KM,

Kalaiselvam K, Kang WT, Al-Maleki AR, et al.

Burkholderia vaccines: Are we moving forward? Front Cell Infect Microbiol. 2013;4(FEB):1-18.

6. Zueter A, Yean CY, Abumarzouq M, Rahman ZA, Deris ZZ. The epidemiology and clinical spectrum of melioidosis in a teaching hospital in a North-Eastern state of Malaysia : a fifteenyear review. BMC Infect Dis [Internet]. 2016;111. Available from: http://dx.doi.org/10.1186/ s12879-016-1583-2

7. How SH, Ng KH, Jamalludin AR, Shah A, Rathor Y. Melioidosis in Pahang, Malaysia. Med J Malaysia. 2005;60.

8. Francis A, Aiyar S, Yean CY, Naing L, Ravichandran M. An improved selective and differential medium for the isolation of Burkholderia pseudomallei from clinical specimens. Diagn Microbiol Infect Dis. 2006;55:95-9.

9. Kim SC, Chen Y, Mirza S, Xu Y, Lee J, Liu P, et al. A clean, more efficient method for insolution digestion of protein mixtures without detergent or urea. J Proteome Res. 2006 Dec;5 (12):3446-52.

10. Gautam SS, Wagh S, Babu S, Gudihal R, Rajagopalan S, Kole P, et al. Relative quantitation of endogenous proteins by quadrupole-time of flight and tandem mass spectrometry. J Chromatogr B, Anal Technol Biomed life Sci. 2019 Feb;1106-1107:11-8.

11. Juvarajah T, Wan-Ibrahim WI, Ashrafzadeh A, Othman S, Hashim OH, Fung SY, et al. Human Milk Fat Globule Membrane Contains Hundreds of Abundantly Expressed and Nutritionally Beneficial Proteins That Are Generally Lacking in Caprine Milk. Breastfeed Med. 2018 Nov;13(9):631-7.

12. Kaestli, M., Richardson, L. J., Colman, R. E., Tuanyok, A., Price, E. P., Bowers, J. R., Mayo, M., Kelley, E., Seymour, M. L., Sarovich, D. S., Pearson, T., Engelthaler, D. M., Wagner, D. M.,
Keim, P. S., Schupp, J. M., \& Currie, B. J. (2012). Comparison of TaqMan PCR assays for detection of the melioidosis agent Burkholderia pseudomallei in clinical specimens. Journal of Clinical Microbiology, 50(6), 2059-2062. https://doi.org/10.1128/JCM.06737-11

13. Zhao, M., Li, M., Yang, Y., Guo, Z., Sun, Y., Shao, C., Li, M., Sun, W., \& Gao, Y. (2017). A comprehensive analysis and annotation of human normal urinary proteome. Scientific Reports, 7(1), 1-13. https://doi.org/10.1038/ s41598-017-03226-6

14. Pauly, H. E., \& Pfleiderer, G. (n.d.). D-Glucose Dehydrogenase from Bacillus megaterium $\mathrm{M}$ 1286: Purification, Properties and Structure. Biological Chemistry, 356(2), 1613-1624. https://doi.org/https://doi.org/10.1515/ bchm2.1975.356.2.1613

15. Chamchoy K, Pumirat P, Reamtong O, Pakotiprapha D, Leartsakulpanich U, Boonyuen U. Functional analysis of BPSS2242 reveals its detoxification role in Burkholderia pseudomallei under salt stress. Sci Rep [Internet]. 2020;10(1):1 -14. Available from: https://doi.org/10.1038/ s41598-020-67382-y

16. Pumirat P, Boonyuen U, Vanaporn M, Pinweha P, Tandhavanant S, Korbsrisate S, et al. The role of short-chain dehydrogenase/ oxidoreductase, induced by salt stress, on host interaction of B. pseudomallei. BMC Microbiol. 2014;14(1):1-11.

17. Smith, J. J., Travis, S. M., Greenberg, E. P., \& Welsh, M. J. (1996). Fail to Kill Bacteria Because of Abnormal Airway Surface Fluid. 85, 229-236. https://doi.org/10.1016/s0092-8674 (00)81099-5

18. Hatrongjit, R., \& Packdibamrung, K. (2010). A novel NADP+-dependent formate dehydrogenase from Burkholderia stabilis 15516: Screening, purification and characterization. Enzyme and Microbial Technology, 46(7), 557-561. https://doi.org/ https://doi.org/10.1016/

j.enzmictec.2010.03.002

19. Young, B. L., Mlamla, Z., Gqamana, P. P., Smit, S., Roberts, T., Peter, J., Theron, G., Govender, U., Dheda, K., \& Blackburn, J. (2014). The 
identification of tuberculosis biomarkers in

human urine samples. European Respiratory

Journal, 43(6), 1719-1729. https://

doi.org/10.1183/09031936.00175113\ 